\title{
Platelet-derived growth factor receptor expression and amplification in choroid plexus carcinomas
}

\author{
Nina N Nupponen ${ }^{1, *}$, Janna Paulsson ${ }^{2, *}$, Astridd Jeibmann ${ }^{3}$, Brigitte Wrede ${ }^{4}$, Minna Tanner ${ }^{5}$, \\ Johannes EA Wolff ${ }^{6}$, Werner Paulus ${ }^{3}$, Arne Östman ${ }^{2}$ and Martin Hasselblatt ${ }^{3}$ \\ ${ }^{1}$ Molecular Cancer Biology Program, University of Helsinki, Helsinki, Finland; ${ }^{2}$ Department of \\ Oncology-Pathology, Cancer Centrum Karolinska, Karolinska Institutet, Stockholm, Sweden; ${ }^{3}$ Institute of \\ Neuropathology, University Hospital Münster, Münster, Germany; ${ }^{4}$ Department of Pediatric Oncology, \\ University of Regensburg, Regensburg, Germany; ${ }^{5}$ Department of Oncology, Tampere University Hospital, \\ Tampere, Finland and ${ }^{6}$ Children's Cancer Hospital, MD Anderson Cancer Center, Houston, TX, USA
}

\begin{abstract}
Platelet-derived growth factor (PDGF) receptor signaling has been implicated in the development of glial tumors, but not yet been examined in choroid plexus carcinomas, pediatric tumors with dismal prognosis for which novel treatment options would be desirable. Therefore, protein expression of PDGF receptors $\alpha$ and $\beta$ as well as amplification status of the respective genes, PDGFRA and PDGFRB, were examined in a series of 22 patients harboring choroid plexus carcinoma using immunohistochemistry and chromogenic in situ hybridization (CISH). The majority of choroid plexus carcinomas expressed PDGF receptors with 6 cases (27\%) displaying high staining scores for PDGF receptor $\alpha$ and 13 cases (59\%) showing high staining scores for PDGF receptor $\beta$. Correspondingly, copy-number gains of PDGFRA were observed in 8 cases out of 12 cases available for $\mathrm{CISH}$ and 1 case displayed amplification (six or more signals per nucleus). The proportion of choroid plexus carcinomas with amplification of PDGFRB was even higher (5/12 cases). PDGFRB amplification status and PDGF receptor $\beta$ protein expression scores were significantly correlated $(P=0.01, S p e a r m a n)$. Expression status of PDGF receptor $\alpha$ or PDGF receptor $\beta$ was not significantly associated with progressionfree survival. To conclude, expression and amplification of PDGF receptors, particularly PDGF receptor $\beta$, are frequent in choroid plexus carcinomas, providing a first rationale for the development of treatments targeting PDGF receptor signaling in these rare malignant pediatric tumors.
\end{abstract}

Modern Pathology (2008) 21, 265-270; doi:10.1038/modpathol.3800989; published online 21 December 2007

Keywords: pediatric neuro-oncology; PDGFRA; PDGFRB; tyrosine kinase receptors; imatinib mesylate; prognosis

Choroid plexus tumors are rare intraventricular neoplasms that account for only $0.4-0.6 \%$ of all intracranial tumors, but represent up to $13 \%$ of brain tumors that occur throughout the first year of life. ${ }^{1}$ In contrast to benign choroid plexus papillomas, choroid plexus carcinomas have a dismal prognosis ${ }^{2-4}$ and are characterized histologically by frank signs of malignancy, that is, brisk mitotic activity, nuclear pleomorphism, increased cellular density, blurring of the papillary growth pattern and

Correspondence: Dr M Hasselblatt, MD, Institute of Neuropathology, University Hospital Münster, Domagkstrasse 19, Münster 48129, Germany.

E-mail: hasselblatt@uni-muenster.de

*These two authors have contributed equally to this work.

Received 9 July 2007; revised 24 September 2007; accepted 1 October 2007; published online 21 December 2007 necrosis. ${ }^{1,2,4}$ Surgery remains the therapeutic mainstay, ${ }^{3,5}$ but due to infiltrative growth and high vascularity of these tumors, gross total resection often cannot be achieved. Chemotherapy and cranial irradiation do improve survival, ${ }^{6,7}$ but the latter is usually not an option in very young children. Therefore, development of novel therapeutic approaches would be desirable.

Platelet-derived growth factor (PDGF) receptors are expressed in the developing brain. ${ }^{8,9}$ PDGFRA null mouse embryos display neural tube defects suggesting that PDGF receptor $\alpha$ signaling is crucial for nervous system development. ${ }^{10}$ Interestingly, PDGF receptor $\alpha$ as well as the structurally related receptor subtype PDGF receptor $\beta$ might play a role in the development of the choroid plexus in rodents. Here, PDGF receptor $\alpha$ has been found to be highly expressed in choroid plexus epithelial cells, ${ }^{8,9}$ 
whereas PDGF receptor $\beta$ has been described to be expressed in the developing choroid plexus vasculature. ${ }^{11}$

Furthermore, PDGF receptor signaling has been shown to contribute to multiple tumor-associated processes as follows: PDGF receptors are involved in different aspects of tumor growth, including autocrine stimulation of malignant cells, angiogenesis and recruitment of tumor stroma ${ }^{12,13}$ and can be inhibited by protein tyrosine kinase inhibitors such as imatinib mesylate (Glivec). Indeed, early clinical studies suggest efficacy of imatinib mesylate in combination with hydroxyurea for the treatment of gliomas. ${ }^{14,15}$ Results from pilot trials employing imatinib mesylate for the treatment of children with solid tumors ${ }^{16}$ as well as recurrent malignant gliomas ${ }^{17}$ point toward a favorable safety profile of imatinib mesylate in that age group.

We therefore investigated protein expression of PDGF receptors $\alpha$ and $\beta$, as well as amplification status of the respective genes, PDGFRA and $P D G F R B$, in a large retrospective series of choroid plexus carcinomas.

\section{Materials and methods}

\section{Patients}

A total of 22 primary choroid plexus carcinomas were retrieved from the archives of the Institute of Neuropathology, University Hospital Münster. All cases were sporadic. Some of the children had been examined as part of the Société Internationale d' Oncologie Pédiatrique choroid plexus tumor study (CPT-SIOP-2000). ${ }^{18}$ All cases were reevaluated neuropathologically according to the current WHO criteria ${ }^{4}$ including immunohistochemistry for INI $1^{19,20}$ as well as choroid plexus-specific markers. ${ }^{20}$ Data on tumor location, extent of surgical resection, adjuvant treatment and postoperative course were compiled by reviewing patient records. Moreover, general practitioners, pediatricians and neurosurgeons were contacted to provide follow-up information on recurrence and survival.

\section{Immunohistochemistry}

Sections were deparaffinized, rehydrated and then washed in distilled $\mathrm{H}_{2} \mathrm{O}$. For antigen retrieval, slides were microwaved for $2 \times 7 \mathrm{~min}$ at $650 \mathrm{~W}$ in antigen retrieval buffer, high $\mathrm{pH}$ (S3307, Dako, Glostrup, Denmark), for PDGF receptor $\beta$, or in 1 mM EDTA pH 8 for PDGF receptor $\alpha$. Sections were then left to cool for at least $30 \mathrm{~min}$ before being washed in PBS with $0.1 \%$ Tween 20 (PBT). Endogenous peroxidase activity was quenched by incubation in PBT containing $3 \% \mathrm{H}_{2} \mathrm{O}_{2}$ for $10 \mathrm{~min}$, then was washed in PBT for $3 \times 5$ min. Slides were blocked in $20 \%$ goat serum diluted in PBT for $30 \mathrm{~min}$ and then incubated with anti-PDGF receptor $\beta$ (no. 3169 rabbit monoclonal, $2 \mu \mathrm{g} / \mathrm{ml}$ (Cell Signaling Technology, Danvers, MA, USA)) or anti-PDGF receptor $\alpha$ (no. 3164 rabbit polyclonal, 1:50 (Cell Signaling Technology)). After washes in PBT, slides were incubated with a biotinylated goat anti-rabbit secondary antibody (E0432, 1:500 (Dako)) for $45 \mathrm{~min}$ at room temperature following incubation with the ABC kit (SK6100, Vectastain ABC-HRP, Vector Laboratories, Burlingame, CA, USA) for 45 min after washing in PBT. The signal was developed using the DAB substrate kit, (SK4100, Vector Laboratories) and sections were counterstained with hematoxylin. PDGF receptor staining was evaluated semiquantitatively by scoring the percentage of stained cells (0 (absent), 1 (<10\%), 2 (10-50\%), 3 (51-80\%), $4(81-100 \%))$ as well staining intensity (0 (absent), 1 (weak), 2 (distinct), 3 (strong)). Both scores were then multiplied to give a maximal staining score of 12 .

\section{Chromogenic In Situ Hybridization}

Freshly cut paraffin-sections for chromogenic in situ hybridization (CISH) were available for 12 of the choroid plexus carcinomas. CISH methodology is described elsewhere in detail. ${ }^{21}$ Briefly, digoxigeninlabeled (DIG-Nick mix Roche, Mannheim, Germany) BAC-probes were used for PDGFRA (a mixture of clones, IDs RP11-117E8 and RP11-626H4) and for PDGFRB (clone ID RP11-754J8, Invitrogen Ltd, Paisley, UK). Gene copy numbers were evaluated using a Leica DM2000 (Leica Microsystems GmbH, Germany) with $\times 63$ and $\times 100$ magnification. Gained gene copy number (low-level amplification) was defined as 3-5 signals per nucleus. Amplification was defined as six or more signals per nucleus.

\section{Statistics}

Comparison of patient characteristics was carried out by Fisher's exact test or Mann-Whitney $U$-test. Probabilities of survival were estimated using the Kaplan-Meier method. The effect of PDGF receptor expression status on the probability of survival was investigated on univariate analysis using the log-rank test. Correlations were tested using the Spearman's test. All statistical analyses were performed using SPSS version 13.0 (SPSS Inc., Chicago, IL, USA).

\section{Results}

\section{Patients}

The median age of the patients was 2 years (quartiles: 1-4 years). Even though the vast majority of tumors was located supratentorially (95\%), gross total resection of the tumors could only be achieved in $50 \%$ of the children. Further patient characteristics have been compiled in Table 1. 
Table 1 Patient characteristics

\begin{tabular}{lc}
\hline Age (median, quartiles) & $2(1-4)$ years \\
Sex (male:female) & $11: 11$ \\
Location & \\
$\quad$ Lateral ventricles & 21 \\
Third ventricle & 0 \\
$\quad$ Fourth ventricle & 1 \\
Treatment & \\
$\quad$ Gross total resection & \\
Radiotherapy & $11(50 \%)$ \\
Chemotherapy & $4(18 \%)$ \\
\end{tabular}

Age, sex, tumor location and treatment of the 22 choroid plexus carcinoma patients.

\section{PDGF Receptor Protein Expression}

The majority of choroid plexus carcinomas expressed PDGF receptor subtypes, particularly PDGF receptor $\beta$. As shown in Figure 1a, PDGF receptor $\alpha$ staining scores were high in 6 cases $(27 \%) ; 3$ cases displayed intermediate staining scores (5-8), whereas low staining scores $(0-4)$ were observed in 13 cases (59\%). The proportion of tumors displaying high staining scores for PDGF receptor $\beta$ was higher: 13 cases (59\%) showed high staining scores for PDGF receptor $\beta$, whereas 6 cases displayed intermediate staining scores (5-8) and only 3 cases (14\%) displayed low staining scores (0-4; Figure 1b). Staining scores for both receptor subtypes were not correlated $(P=0.56)$; only three cases displayed high staining scores for both receptor subtypes.

\section{PDGF Receptor Amplification}

Gained gene copy numbers of PDGFRA were observed in 8 out of the 12 cases in which PDGFRA amplification status could be examined (Figure 1e). One single case displayed PDGFRA amplification. This supratentorial choroid plexus carcinoma in a 12-year-old boy also displayed a high staining score for PDGF receptor $\alpha$. In two cases, CISH for PDGFRA yielded no results. Gained gene copy numbers or amplification of PDGFRB were encountered in five cases each (Figure 1f). PDGFRB amplification status and PDGF receptor $\beta$ protein expression scores were significantly correlated $(P=0.01$, Spearman). All cases with PDGFRB amplification displayed high PDGFR receptor $\beta$ protein staining scores. Simultaneous amplification of both PDGFRA and PDGFRB was not observed.

\section{PDGF Receptor Status and Prognosis}

Prognosis was poor in the 20 patients for whom information on follow-up could be obtained: median recurrence-free survival accounted for only 22 months. On log-rank test, protein expression status of PDGF receptors $\alpha$ or $\beta$ was not significantly associated with progression-free survival. Because the number of cases available for CISH was even smaller, the effect of amplification status on progression-free survival was not statistically evaluated.

\section{Discussion}

As PDGF receptor signaling is strongly linked to central nervous system and choroid plexus development and has been shown to contribute to multiple tumor-associated processes, we conducted analyses of protein expression status and gene copy number of PDGF receptors in choroid plexus carcinomas. To our knowledge, our series is among the largest published to date and the first to report protein expression of PDGF receptors $\alpha$ and $\beta$ as well as copy number increases of PDGFRA or PDGFRB in the majority of choroid plexus carcinomas examined. In addition, PDGRB amplification significantly correlated to PDGF receptor $\beta$ protein expression, suggesting that increased copy number may trigger abnormal protein overexpression, potentially stimulating malignant tumor growth.

PDGF receptors and their ligands have an established role in the development and progression of human gliomas: gene amplification and overexpression of PDGFRA are found in up to $33 \%$ of malignant gliomas ${ }^{22,23}$ and might stimulate tumor growth by autocrine PDGF receptor signaling. ${ }^{12,13}$ In a recent study on pediatric gliomas, PDGFRA was found to be amplified in 2 out of 14 malignant gliomas but not in any of the low-grade tumors examined. ${ }^{24}$ Expression of PDGF receptors $\alpha$ and $\beta$ has also been described in ependymomas ${ }^{25}$ as well as primitive neuroectodermal tumors and medulloblastomas, ${ }^{26}$ but gene amplification has not yet been described in these pediatric tumors. Interestingly, however, PDGF receptors have been shown to be preferentially expressed in medulloblastomas showing aggressive biological behavior with metastatic spread, ${ }^{27,28}$ suggesting not only a role in the promotion of tumor growth but also prognostic significance of PDGF receptor expression. In the present retrospective series, the proportion of choroid plexus carcinomas expressing PDGF receptors was high and treatments employed were heterogeneous. Therefore, the absent prognostic value of PDGF receptor expression status is not too discouraging. Determination of PDGF receptor status will certainly be of value in future therapeutic trials assessing the efficiency of treatments targeting PDGF receptor signaling in choroid plexus carcinomas.

In contrast to myeloproliferative disease, ${ }^{29}$ constitutive activating mutations of PDGF receptors seem to be rare events in central nervous system tumors. ${ }^{30}$ Therefore, further functional studies on the role of PDGF receptor signaling in the tumorigenesis of choroid plexus carcinomas are clearly 
a

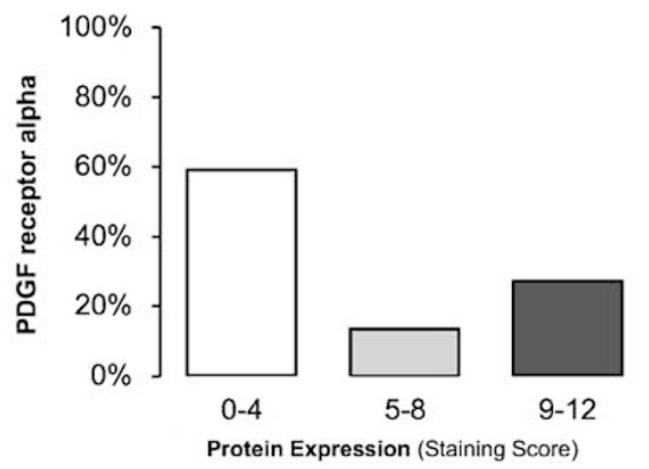

C

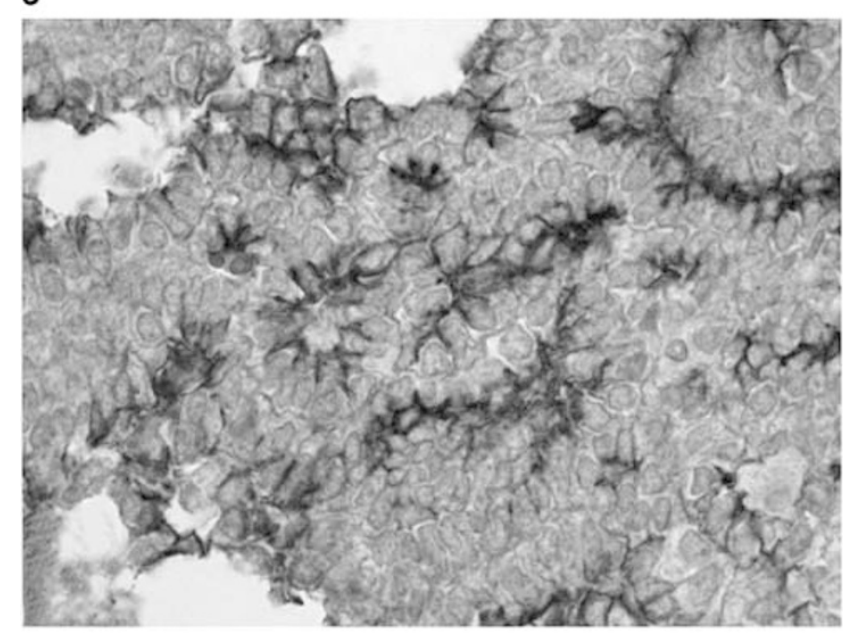

e
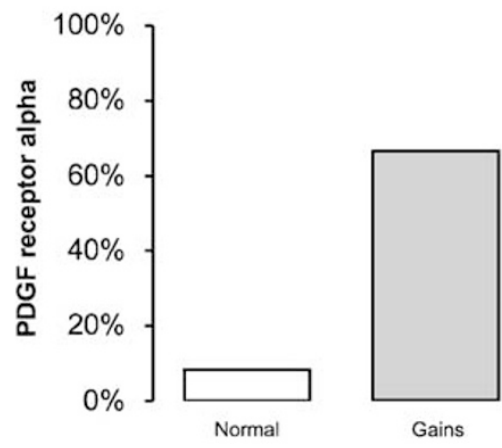

Gains
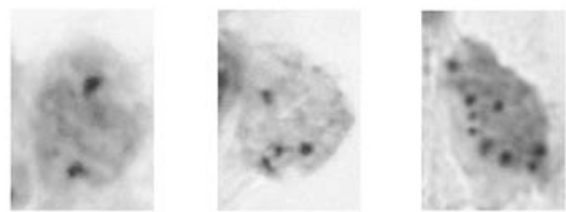

b

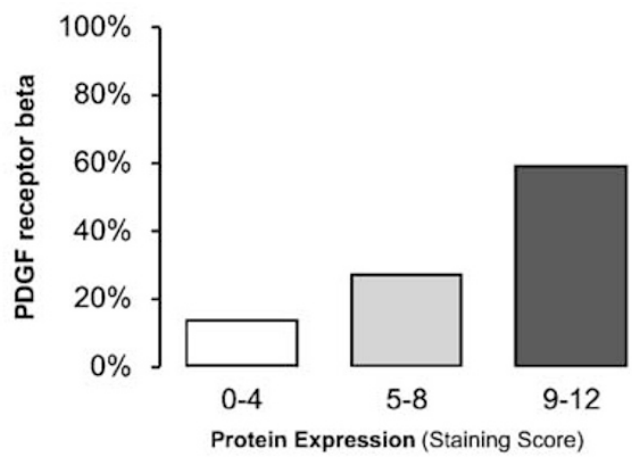

d
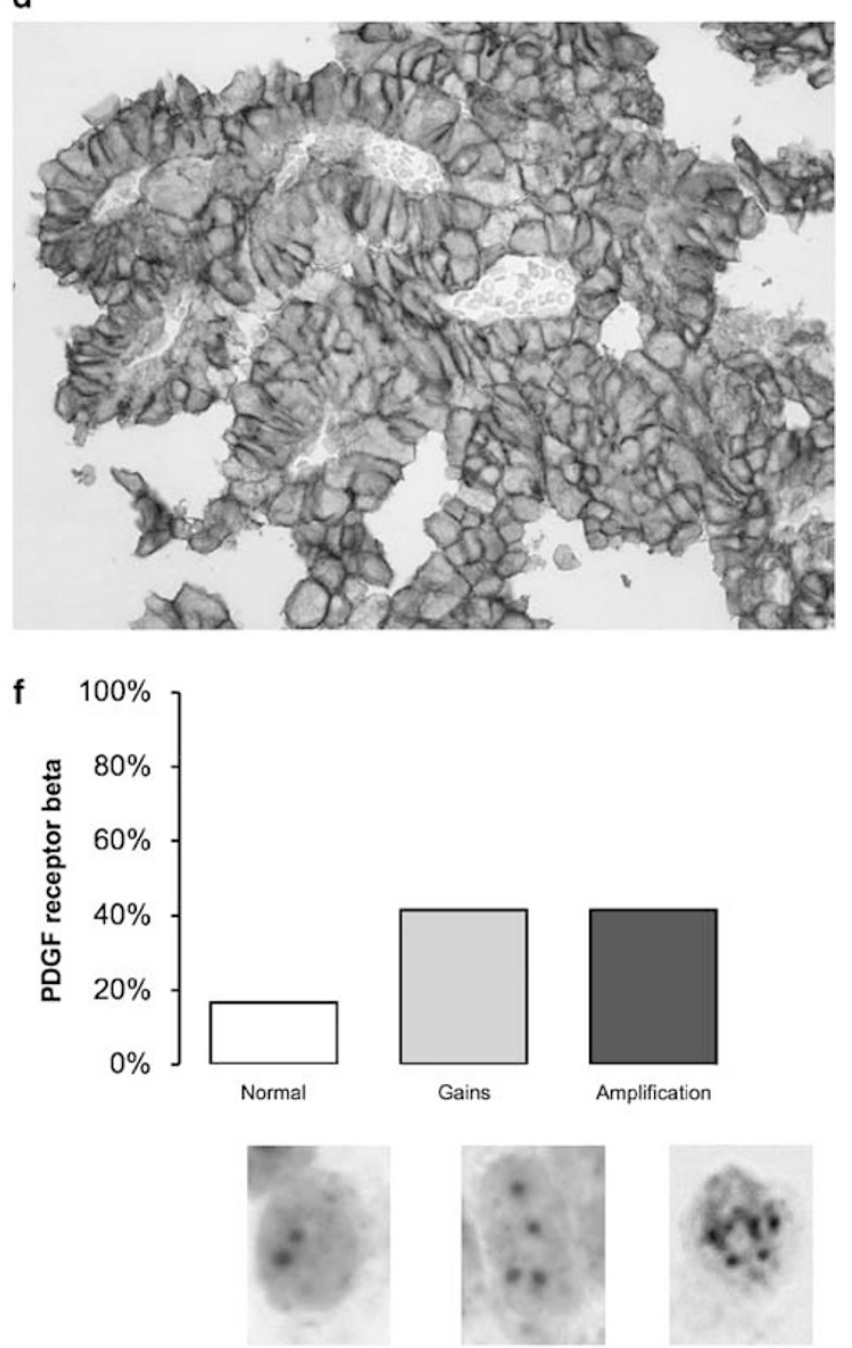

Figure 1 Platelet-derived growth factor (PDGF) receptor protein expression and amplification. Proportion of choroid plexus carcinomas displaying low (0-4), intermediate (5-8) or high (9-12) staining scores as well as representative images depicting high immunohistochemistry staining scores for PDGF receptor $\alpha$ (a and $\mathbf{c}$ ) and PDGF receptor $\beta$ (b and d) as well as proportion of tumors with copy number gains or amplification as well as representative CISH images for PDGFRA (e) and PDGFRB (f).

needed before definite conclusions on the functional role of PDGF receptors in the development of choroid plexus carcinoma can be drawn. However, such studies are hampered by the fact that besides immortalized rat choroid plexus epithelial cells, ${ }^{31}$ true choroid plexus carcinoma cell lines have not yet been established.

To conclude, expression and amplification of PDGF receptors, particularly PDGF receptor $\beta$, is frequent in choroid plexus carcinomas providing a 
first rationale for the development of treatments targeting PDGF receptor signaling in choroid plexus carcinomas.

\section{Acknowledgements}

NNN is supported by the Academy of Finland, K Albin Johansson Foundation and Instrumentarium Foundation. JP and AÖ are supported by Cancerfonden, Swedish Research Council, Cancerföreningen and Gustaf V:s Jubileumsfond. AJ, WP and $\mathrm{MH}$ are supported by Deutsche Krebshilfe (Grant 106156). We thank Drs Pietsch and Becker, Brain Tumor Reference Centre of the German Association of Neuropathology and Neuroanatomy at the Institute of Neuropathology, Bonn for kind collaboration. Drs Brodhun (Jena), von Deimling (Berlin), Geiger (Dresden), Hofstädter (Regensburg), Hugo (Kiel), Jellinger (Vienna), König (Göttingen), Kretzschmar (Munich), Kuchelmeister (Giessen), Maier (Innsbruck), Reifenberger (Düsseldorf), Roggendorf (Würzburg) and Volk (Freiburg) kindly provided archival tissues. Barbara Riesmeier provided expert technical assistance and Ralf Mersmann kindly assisted in the preparation of the figure.

\section{Disclosure/conflict of interest}

The authors state no conflict of interest to declare.

\section{References}

1 Rickert CH, Paulus W. Tumors of the choroid plexus. Microsc Res Tech 2001;52:104-111.

2 Jeibmann A, Hasselblatt M, Gerss J, et al. Prognostic implications of atypical histologic features in choroid plexus papilloma. J Neuropathol Exp Neurol 2006;65: 1069-1073.

3 Wolff JE, Sajedi M, Brant R, et al. Choroid plexus tumours. Br J Cancer 2002;87:1086-1091.

4 Paulus W, Brandner S. Choroid plexus tumours. In: Louis DN, Ohgaki H, Wiestler O, Cavenee WK (eds). World Health Organization Classification of Tumors. Pathology and Genetics of Tumours of the Nervous System, 4th edn. IARC Press: Lyon, 2007, pp 82-85.

5 Wrede B, Liu P, Ater J, et al. Second surgery and the prognosis of choroid plexus carcinoma-results of a meta-analysis of individual cases. Anticancer Res 2005;25:4429-4433.

6 Wolff JE, Sajedi M, Coppes MJ, et al. Radiation therapy and survival in choroid plexus carcinoma. Lancet 1999;353:2126.

7 Wrede B, Liu P, Wolff JE. Chemotherapy improves the survival of patients with choroid plexus carcinoma: a meta-analysis of individual cases with choroid plexus tumors. J Neurooncol 2007;85:345-351.

8 Schatteman GC, Morrison-Graham K, van Koppen A, et al. Regulation and role of PDGF receptor alphasubunit expression during embryogenesis. Development 1992;115:123-131.
9 Pringle NP, Mudhar HS, Collarini EJ, et al. PDGF receptors in the rat CNS: during late neurogenesis, PDGF alpha-receptor expression appears to be restricted to glial cells of the oligodendrocyte lineage. Development 1992;115:535-551.

10 Sun T, Jayatilake D, Afink GB, et al. A human YAC transgene rescues craniofacial and neural tube development in PDGFRalpha knockout mice and uncovers a role for PDGFRalpha in prenatal lung growth. Development 2000;127:4519-4529.

11 Shinbrot E, Peters KG, Williams LT. Expression of the platelet-derived growth factor beta receptor during organogenesis and tissue differentiation in the mouse embryo. Dev Dyn 1994;199:169-175.

12 Östman A, Heldin CH. PDGF receptors as targets in tumor treatment. Adv Cancer Res 2007;97:247-274.

13 Östman A. PDGF receptors-mediators of autocrine tumor growth and regulators of tumor vasculature and stroma. Cytokine Growth Factor Rev 2004;15: 275-286.

14 Dresemann G. Imatinib and hydroxyurea in pretreated progressive glioblastoma multiforme: a patient series. Ann Oncol 2005;16:1702-1708.

15 Reardon DA, Egorin MJ, Quinn JA, et al. Phase II study of imatinib mesylate plus hydroxyurea in adults with recurrent glioblastoma multiforme. J Clin Oncol 2005;23:9359-9368.

16 Bond M, Bernstein ML, Pappo A, et al. A phase II study of imatinib mesylate in children with refractory or relapsed solid tumors: A Children's Oncology Group Study. Pediatr Blood Cancer 2007; [E-pub ahead of print].

17 Pollack IF, Jakacki RI, Blaney SM, et al. Phase I trial of imatinib in children with newly diagnosed brainstem and recurrent malignant gliomas: a pediatric brain tumor consortium report. Neuro Oncol 2007;9: 145-160.

18 Wrede B, Peters O, Kebudi R, et al. Choroid Plexus tumors in CPT-SIOP-2000: update March 2006 [abstract]. Pediatric Blood Cancer 2006;47:382.

19 Judkins AR, Burger PC, Hamilton RL, et al. INI1 protein expression distinguishes atypical teratoid/ rhabdoid tumor from choroid plexus carcinoma. J Neuropathol Exp Neurol 2005;64:391-397.

20 Hasselblatt M, Böhm C, Tatenhorst L, et al. Identification of novel diagnostic markers for choroid plexus tumors: a microarray-based approach. Am J Surg Pathol 2006;30:66-74.

21 Blom T, Tynninen O, Puputti M, et al. Molecular genetic analysis of the REST/NRSF gene in nervous system tumors. Acta Neuropathol 2006;112:483-490.

22 Joensuu H, Puputti M, Sihto H, et al. Amplification of genes encoding KIT, PDGFRalpha and VEGFR2 receptor tyrosine kinases is frequent in glioblastoma multiforme. J Pathol 2005;207:224-231.

23 Puputti M, Tynninen O, Sihto H, et al. Amplification of KIT, PDGFRA, VEGFR2, and EGFR in gliomas. Mol Cancer Res 2006;4:927-934.

24 Wong KK, Tsang YT, Chang YM, et al. Genome-wide allelic imbalance analysis of pediatric gliomas by single nucleotide polymorphic allele array. Cancer Res 2006;66:11172-11178.

25 Black P, Carroll R, Glowacka D. Expression of plateletderived growth factor transcripts in medulloblastomas and ependymomas. Pediatr Neurosurg 1996;24:74-78.

26 Smits A, van Grieken D, Hartman M, et al. Coexpression of platelet-derived growth factor alpha and beta 
receptors on medulloblastomas and other primitive neuroectodermal tumors is consistent with an immature stem cell and neuronal derivation. Lab Invest 1996;74:188-198.

27 MacDonald TJ, Brown KM, LaFleur B, et al. Expression profiling of medulloblastoma: PDGFRA and the RAS/ MAPK pathway as therapeutic targets for metastatic disease. Nat Genet 2001;29:143-152.

28 Gilbertson RJ, Clifford SC. PDGFRB is overexpressed in metastatic medulloblastoma. Nat Genet 2003;35: 197-198.
29 Golub TR, Barker GF, Lovett M, et al. Fusion of PDGF receptor beta to a novel ets-like gene, tel, in chronic myelomonocytic leukemia with $\mathrm{t}(5 ; 12)$ chromosomal translocation. Cell 1994;77:307-316.

30 Gilbertson RJ, Langdon JA, Hollander A, et al. Mutational analysis of PDGFR-RAS/MAPK pathway activation in childhood medulloblastoma. Eur J Cancer 2006;42:646-649.

31 Zheng W, Zhao Q. Establishment and characterization of an immortalized Z310 choroidal epithelial cell line from murine choroid plexus. Brain Res 2002;958:371-380. 